\title{
Solvent Based Slurry Functional Graded Thermal Barrier Coating for Application in Automotive Turbocharger Turbine Volute Casing
}

\author{
Alias Mohd Noor ${ }^{*}$, Muhammad Rabiu Abbas, Uday M. Basheer
}

\begin{abstract}
Tremendous amount of heat is being lost at the turbine area of an automotive turbocharger during its operation. Application of ceramic thermal barrier coating to components operating under severe temperature condition such as automotive turbocharger turbine volute casing can reduce the heat lost to the environment, improve the efficiency and reliability of components and extend their service life. But high cost of installation and maintenance, complexity and spallation problem due to thermal expansion mismatch between the ceramic and the metal substrate have seriously restricted the acceptance and widespread practice of ceramic thermal barrier coating. In the present study, a solvent based slurry functionally graded thermal barrier coating technique was employed in depositing different compositions of Yttria stabilized zirconia and nickel powders on a nickel alloy substrate using a simple laboratory-scale surface coating machine. The coating compositions of $25 \mathrm{wt} \%$ YSZ \& $75 \mathrm{wt} \% \mathrm{Ni}, 60 \mathrm{wt} \%$ YSZ \& $40 \mathrm{wt} \% \mathrm{Ni}$ and $75 \mathrm{wt} \% \mathrm{YSZ} \& 25 \mathrm{wt} \% \mathrm{Ni}$ were used for the deposition of the first layer, second layer and third layer of the functionally graded coating on the nickel substrate respectively. Experimental validation of heat transfer across the coating and adhesion tests were used to evaluate the suitability and integrity of the functionally graded coating produced for the intended application. The coating microstructure was also analyzed using optical microscope, scanning electron microscopy (SEM) and energy dispersive X-ray (EDX). The results have shown that, the functionally graded coating produced has the heat resistance capability of $35^{\circ} \mathrm{C}, 140^{\circ} \mathrm{C}$ and $250^{\circ} \mathrm{C}$ for one layer, two layer and three layer respectively. The adhesion strength of the coating improved with an increase in the number of the coating layers. There was no spallation problem observed from the coating, also no crack or deformation was observed from the results of the microstructural analysis of the functionally graded coating after the experimental heat transfer tests.
\end{abstract}

Keywords- Automotive turbocharger, Thermal barrier coating, Heat transfer, Slurry

Alias Mohd Noor *(corresponding author)

Universiti Teknologi Malaysia

Malaysia

Muhammad Rabiu Abbas

Hassan Usman Katsina Polytechnic

Nigeria

Uday M. Basheer

Universiti Teknologi Malaysia

\section{Introduction}

Turbocharging is the common technique of increasing power density of internal combustion engine, when used with the downsizing technique, it reduced the fuel consumption and pollutant emission [1-3]. Turbocharger used the extracted energy of the engine hot exhaust gas by expanding it through the turbine which in turn drives the compressor by a shaft and compress ambient air into the engine cylinder via the intake manifold. However, studies have shown that thermal energy transfer from the turbocharger turbine seriously affects the turbine power and in turn affects the overall turbocharger performance [4-6]. On the other hand, experimental data from several studies have shown that insulating the turbocharger turbine can significantly improve the non-adiabatic performance of the turbocharger and hence the overall engine efficiency $[4,7$, $8]$.

Developments in advanced structural ceramics and their composite had opened a new chapter for the design and fabrication of mechanical structural components that can withstand severe conditions of temperature without serious changes to their mechanical properties. Advanced ceramics are the most thoroughly characterized materials and have become prime candidates for engineers and designers in a variety of wide range of applications which include heat exchangers, gas turbines, automotive engine components such as valves and tappets for cam followers, non-resonance knock sensors, spark plugs, turbocharger turbine rotors and housings as well as other wear resistance components subjected to elevated temperature conditions [9-13]. Their incorporation by Daimler-Benz as engine valves of some diesel engines and as high temperature components made by AlliedSignal for supplementary power unit of turbo engines and several turbine engine components [14] as well as the Rolls Royce Allison and Solar turbine programmes for the production of gas turbine components made from ceramics [15] are indications which demonstrated their practical capability, durability and reliability. Automotive vehicles which travel long distances have the problem of periodic replacement of worn parts. The use of ceramics as wear parts can solve this problem because of their exceptional resistance to wear [12].

Thermal barrier coating is a thin layer of material(s) having high insulating properties which are bonded to a metal substrate to insulate and protect it from temperature excursion or damage by foreign object. Thermal barrier coating materials selection is constrained by requirements like lower thermal conductivity, high melting 
point, good adhesion to substrate, chemical inertness, lower thermal expansion mismatch with the substrate as well as absence of phase transformation between operation and room temperatures [16]. Hitherto, only a few ceramic materials had been found to basically satisfy the basic requirements of thermal barrier coating, and among these materials Yttria Stablized Zirconia (YSZ) is the most generally used and studied material for thermal barrier coating application due to its excellent performance capabilities in applications operating under severe temperature condition like gas turbine and diesel engines [16-19]. Many applications including but not restricted to automotive industry, gas turbine, nuclear industries, aerospace and heavy-duty utilities such as diesel trucks have benefited from one of thermal barrier coating techniques [20-30]. Functionally graded thermal barrier coating (FGTBC) is a new thermal barrier coating technique consisting of non-homogeneous materials whose composition and microstructure are varied according to a predetermined profile in order to enhance its thermo-mechanical properties and reduced spallation problems occurring in thermal barrier coated engineering materials [31-33]. Two or more different materials powder in most cases ceramic and metal are being mixed and used depending on the objective, applications and the nature of the substrate material. Research findings have also indicated that Nickel powder effectively reduce residual thermal stresses between the ceramic coating and the substrate through reducing the thermal expansion mismatch between them [33, 34]. The automatic film application technique is a new and relatively less expensive process for fabricating surface coatings using automatic film applicator machine. The machine is equipped with different wirewound bars with very small gaps based on the user requirements in order to have the required coating thickness similar to those frequently used for thermal barrier coating applications [35-37]. It has the advantages of accuracy, simplicity, and reproducibility, thus eliminating uncertainty and human error $[36,38]$. The aim of the present research is to evaluate the quality, integrity and reliability of a functionally graded thermal barrier coating (FG-TBC) produced using automatic film applicator machine for use in automotive turbocharger turbine volute casing.

\section{Materials and methods}

\subsection{Materials}

The raw materials used in this study were commercially obtained Yttria stabilized zirconia (YSZ) powder $(90.90 \mathrm{ZrO} 2,7.14 \mathrm{Y} 2 \mathrm{O} 3,1.96 \mathrm{HfO} 2)$ from SigmaAldrich, UK, having average particle size of $0.38 \mu \mathrm{m}$ with commercially purity of $99.9 \%$ and Nickel powder $(95.8 \mathrm{Ni}$, $4.2 \mathrm{Fe}$ ) from Sigma-Aldrich, USA, having average particle size of $1.24 \mu \mathrm{m}$ with commercial purity of $99.99 \%$. Other coating materials used included Polyvinyl alcohol (PVA) from Sigma-Aldrich, USA, with commercial purity $99 \%$ serving as the binder, an Ammonium citrate tribasic dispersant from Sigma-Aldrich, Germany, with commercial purity $97 \%$ and distilled water. Also a commercially obtained Nickel alloy $(95.4 \mathrm{Ni}, 4.17 \mathrm{Co}, 0.148 \mathrm{Ti}, 0.078 \mathrm{Zr}$, $0.025 \mathrm{Cr}_{2}, 0.025 \mathrm{Mo}, 0.019 \mathrm{C}, 0.018 \mathrm{Cu}_{2}, 0.011 \mathrm{Mn}, 0.0047 \mathrm{~Pb}$,
0.002Mg, 0.002P) from Baoji Tianbang Ti \& Ni Co., China, was used in this study as the substrate material for the FGTBC coatings.

\section{$2.2 \quad$ The coating method}

In the present study, the nickel alloy substartes were cut into the dimension of $60 \mathrm{mmx} 30 \mathrm{mmx} 4 \mathrm{~mm}$ and were sand blasted using sand blasting machine (Growell Manufacturing, Thailand). The substrate were then degrease with acetone for 15 minutes and kept in ethanol before coating. Approptriate compositions of the YSZ-nickel powder were then mixed with the percentage weight propotion of $25 \mathrm{wt} \% \mathrm{YSZ}-75 \mathrm{wt} \% \mathrm{Ni}, 60 \mathrm{wt} \% \mathrm{YSZ}-40 \mathrm{wt} \% \mathrm{Ni}$ and $75 \mathrm{wt} \% \mathrm{YSZ}-25 \mathrm{wt} \% \mathrm{Ni}$ for the first, second and third layer respectively. The ceramic-metal composition was ball milled for three hours in the presence of approriate percentage of binder, dispersant and solvent to produce the required coating slurry. An automatic film applicator (Sheen Instruments, UK) was used for coating the nickel alloy substrate with the FG-TBC slurry composition. The coated samples were then allowed to dry under atmospheric condition for 48 hours after which they were further dried in an oven at a temperature of $100^{\circ} \mathrm{C}$ for 2 hours before proceeding to the sintering stage. The binder removal and sintering stages of the FG-TBC were carried out in a controlled environment. A programmable KSL-1800X high temperature muffle furnace from MTI Corporation, USA, was used for this purpose in the presence of Argon air. The samples were subjected to a heating rate of approximately 7 ${ }^{\circ} \mathrm{C} / \mathrm{min}$ up to the time the temperature reached $650{ }^{\circ} \mathrm{C}$ where it was hold at that point for 20 minutes in order to effectively remove the binder there present in the coating. Then after the binder removal the temperature in the furnace was raised to $1200{ }^{\circ} \mathrm{C}$ and the samples were hold at that point for 60 minutes to ensure effective sintering of the nickel powder contained in the FG-TBC composition. The coated FG-TBC samples were tested on a high temperature test rig to evaluate their thermal resistance capability, quality and reliability. Furthermore, in order to evaluate the bonding strength of the FG-TBC, a pull-off adhesion testing method was employed on all the samples for both before and after the high temperature test using PosiTest automatic adhession tester (AT-A DeFelsko Corporation, USA).

\section{Results and Discussion}

The microstructure of the FG-TBC taken using optical microscope (OM) is shown in Fig. 1, while Fig 2-3 shows the scanning electron micrsocopy (SEM) images of the FG-TBC samples for both before and after the high temperature testing. As can be seen from the figures, there was no deformation or crack or spallation problem observed on all the images of the coating for both before and after the high temperature test. This is a clear indication of the integrity, durability and reliability of the FG-TBC produced. 
Proc. of The Fifth Intl. Conf. On Advances in Mechanical, Aeronautical and Production Techniques - MAPT 2016 Copyright (C) Institute of Research Engineers and Doctors, USA .All rights reserved.

ISBN: 978-1-63248-090-3 doi: 10.15224/ 978-1-63248-090-3-48
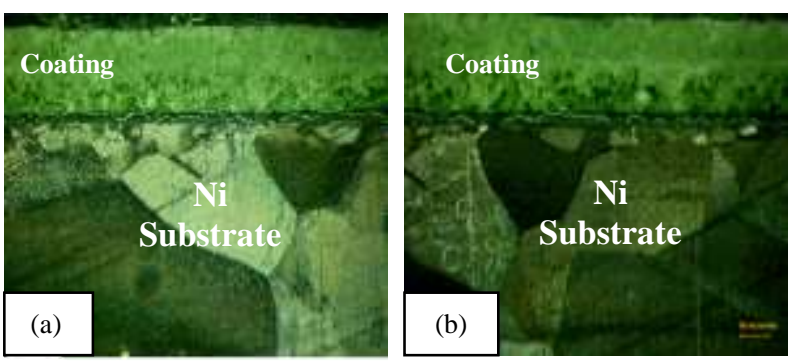

Fig. 1 Optical images of FG-TBC (a) before testing (b) after testing
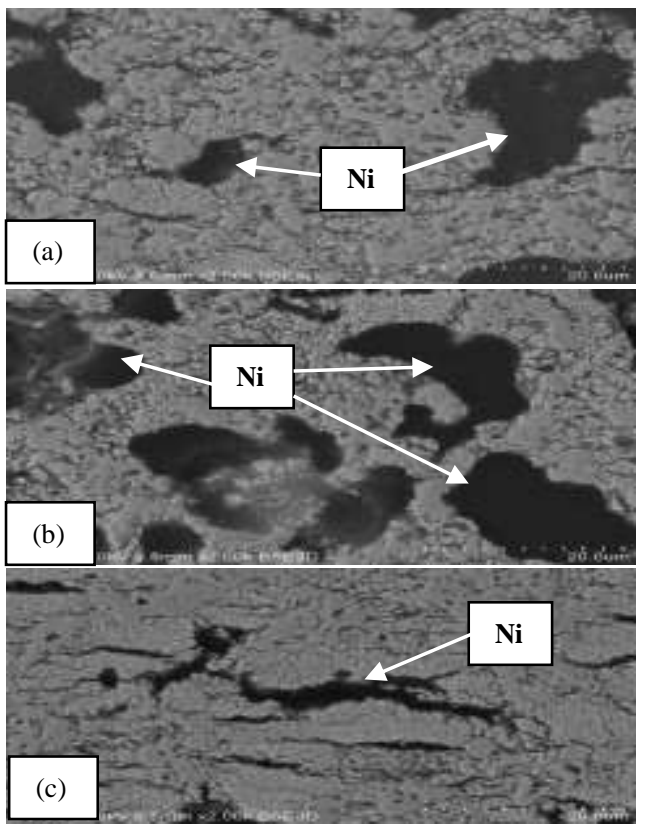

Fig. 2 SEM images of FG-TBC before testing (a) 1 layer (b) 2 layer (c) 3 layer
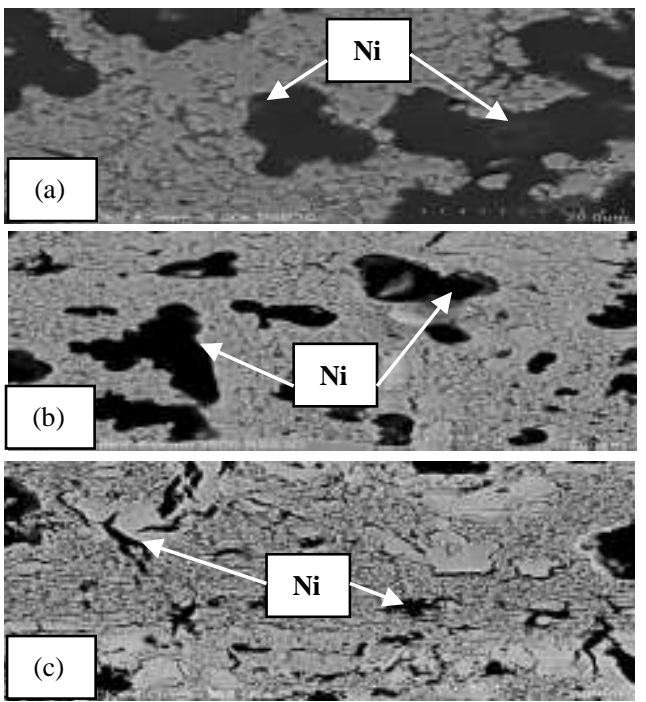

Fig. 3 SEM images of FG-TBC after testing (a) 1 layer (b) 2 layer (c) 3 layer

Fig. 4 shows the line scane EDX result of a three layer FG-TBC for both before and after the high temperature test. The presence of high peak of zirconia in the EDX result is a clear demonstration of the high insulation capability of the FG-TBC produced due to the fact that zirconia ceramic has a very low thermal conductivity. It was observed that there is a high peaks of carbon in the EDX result of the FGTBC after testing which can be attributed to the fact that the carbon comes from the flame used (ie Oxy-acetelyne flame) during the high temperature test and as a result can be concluded that a 'curburizing' flame category of the oxyacetelyne was dominant flame used during the test.
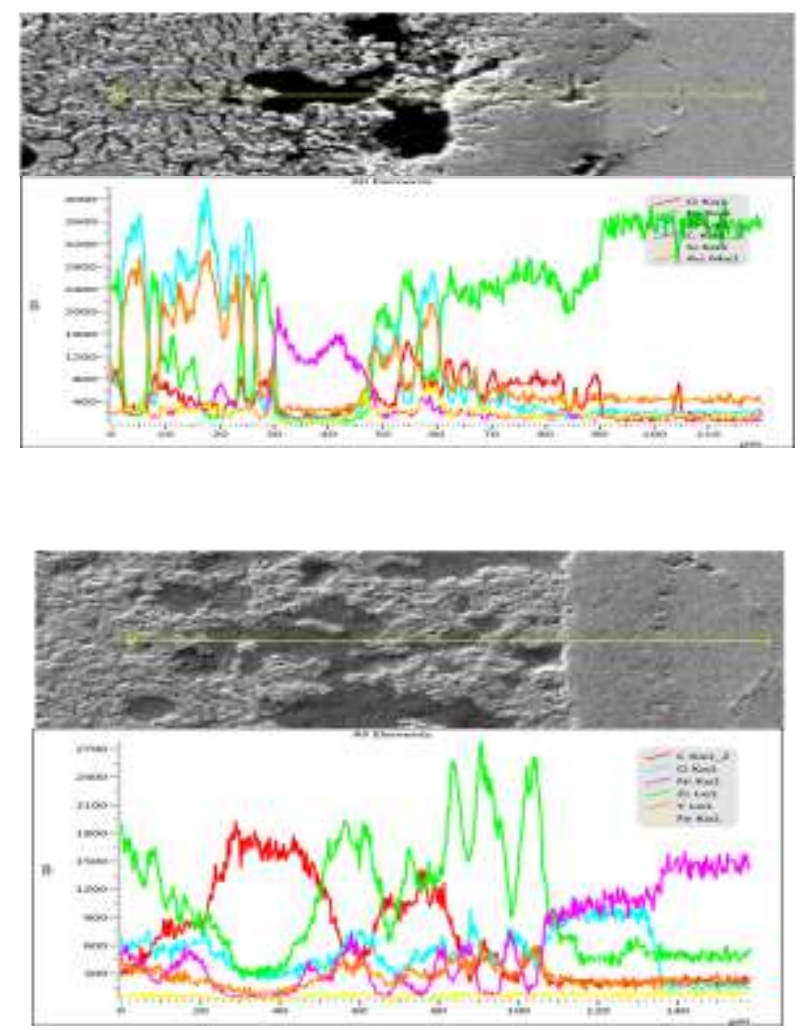

Fig. 4 Line-scan EDX of 3 layer FG-TBC (a) before testing (b) after testing

In all the EDX results of both before and after the high temeprature test, an intermetallic layer can be clearly observed between the substrate and the coating, this is also an added advantage to the FG-TBC strength and probabily that is what has give its adhesion strength. Table 1 shows the result of the experimental heat resistance ability of the FGTBC samples. It was observed that the heat resistance increase with an increase in the number of coating layers. This can be attributed to the increase in the YSZ composition in the layers as well as the coating thickness since they all increase as the number of layers increases. While Table 2 shows the result of the adhesion test conducted on the FG-TBC samples for both before and after the high temperature test. It can be seen that the adhession strength of the coating increase with an increase in the coating layer and ofcourse with an increase in the number of the sintering cycles since after each FG-TBC layer deposition it must undergo cycle of sintering process before another layer can be deposited. 
Proc. of The Fifth Intl. Conf. On Advances in Mechanical, Aeronautical and Production Techniques - MAPT 2016 Copyright (C) Institute of Research Engineers and Doctors, USA .All rights reserved.

ISBN: 978-1-63248-090-3 doi: 10.15224/ 978-1-63248-090-3-48

Table 1 Experimental heat resistance ability of the FG-TBC

\begin{tabular}{|c|c|c|c|}
\hline S/No. & $\begin{array}{c}\text { Layer } \\
\text { number }\end{array}$ & $\begin{array}{c}\text { FG-TBC layer } \\
\text { composition }\end{array}$ & $\begin{array}{c}\text { Total } \\
\text { temperature } \\
\text { reduction } \\
\left({ }^{\circ} \mathbf{C}\right)\end{array}$ \\
\hline 1 & First & $\begin{array}{c}25 \mathrm{wt} \% \mathrm{YSZ}- \\
75 \mathrm{wt} \% \mathrm{Ni}\end{array}$ & 35 \\
\hline 2 & Second & $\begin{array}{c}60 \mathrm{wt} \% \mathrm{YSZ}- \\
40 \mathrm{wt} \% \mathrm{Ni}\end{array}$ & 140 \\
\hline 3 & Third & $\begin{array}{c}75 \mathrm{wt} \% \mathrm{YSZ}- \\
25 \mathrm{wt} \% \mathrm{Ni}\end{array}$ & 250 \\
\hline
\end{tabular}

Table 2 The adhesion strength of the FG-TBC

\begin{tabular}{|c|c|c|c|}
\hline S/No. & Layer & $\begin{array}{c}\text { Adhesion } \\
\text { before testing } \\
\text { (MPa) }\end{array}$ & $\begin{array}{c}\text { Adhesion } \\
\text { after testing } \\
\text { (MPa) }\end{array}$ \\
\hline 1 & One layer & 2.63 & 2.88 \\
\hline 2 & Two layer & 3.08 & 3.07 \\
\hline 3 & Three layer & 3.59 & 3.44 \\
\hline
\end{tabular}

\section{Conclusions}

In this study, slurry based functionally graded thermal barrier coating was successfully deposited on nickel metal alloy for use as an automotive turbocharger turbine volute casing material. The microstructural examination of all the FG-TBC produced had revealed their integrity and durability. The thermal resistance results of the FG-TBC and their subsequent adhesion strength results have both demonstrated the suitability and reliability of the FG-TBC on the nickel alloy substrate for use as a turbocharger turbine volute casing material.

\section{Acknowledgment}

The authors would like to thanks the UTM-Centre for Low Carbon Transport in cooperation with Imperial College London, Faculty of Mechanical Engineering and Universiti Teknologi Malaysia (UTM) for providing the research facilities. This research work has been supported by the UTM Research University Grant (01G51) and the grant (4F445) from Ministry of Ministry of Education Malaysia (MOE).

\section{References}

[1] F. Hellstrom, Technical Reports of Royal Institute of Technology, Sweden, (2010).

[2] F. Bozza, V. De Bellis, ASME Journal of Engineering for Gas Turbines and Power, 136 (2014) 1-13.

[3] M. Holger, V. Mathias, B. Roland, K. Andreas, ASME Journal of Engineering for Gas Turbines and Power, 136 (2014) 1-12.

[4] S. Shaaban, J. Seume, International Journal of Rotating Machinery, 2012 (2012) 1-11.

[5] A. Romagnoli, R. Martinez-Botas, Applied Thermal Engineering, 38 (2012) 58-77.

[6] L. Barelli, G. Bidini, F. Bonucci, Energy Conversion and Management, 68 (2013) 28-39.

[7] M. Cormerais, P. Chesse, J. Hetet, Int. Journal of Thermodynamics, 12 (2009) 193-202.
[8] N. Baines, K.D. Wygant, A. Dris, ASME Journal of Engineering for Gas Turbines and Power, 132 (2010) 1-8.

[9] S. Sajgalik, K. Rajan, P. Warbichler, F. Hoffer, J. Dusza, Key Engineering Materials, 159-160 (1999) 405-410.

[10] H. Emoto, H. Hirotsuru, M. Mitomo, Key Engineering Materials, 159160 (1999) 251-220.

[11] K.M. Fox, J.R. Hellmann, International Journal of Applied Ceramic Technology, 5 (2008) 138-154.

[12] A. Okada, Journal of the European Ceramic Society, 28 (2008) 10971104.

[13] P. Gui-hua, L. Xiang-guo, L. Min, L. Zhen-hua, L. Quilan, L. Wenlan, Scripta Materialia, 61 (2009) 347-350.

[14] M.H. Bocanegra-Bernal, B. Matovic, Materials Science and Engineering: A, 527 (2010) 1314-1338.

[15] H.-T. Lin, M.K. Ferber, W. Westphal, F. Macri, Proceedings of ASME Internal Combustion Engine Conference, Amsterdam, The Netherlands, (2002) 147-154.

[16] X.Q. Cao, R. Vassen, D. Stoever, Journal of the European Ceramic Society, 24 (2004) 1-10.

[17] S. Salman, K. Ramazan, L. Urtekin, F. Findik, Materials and Design, 27 (2006) 585-590.

[18] C. Amaya, W. Aperador, J.C. Caicedo, F.J. Espinoza-Beltran, J. Munoz-Saldana, G. Zambrano, P. Prieto, Corrosion Science, 51 (2009) 2994-2999.

[19] M. Keshavarz, M.H. Idris, N. Ahmad, Journal of Advanced Ceramics, 2 (2013) 333-340

[20] I. Gurrappa, A. Sambasiva Rao, Surface and Coatings Technology, 201 (2006) 3016-3029.

[21] N. Phuc, The University of Adelaide, Australia: PhD Thesis, 2010.

[22] J.R. Price, O. Jimenez, L. Faulder, B. Edwards, V. Parthasarathy, Journal of Engineering Gas Turbine and Power, 121 (1999) 586-592.

[23] N.P. Padture, M. Gell, E.H. Jordan, Science, 296 (2002) 280-284.

[24] F. Alhama, A. Campo, Applied Thermal Engineering, 23 (2003) 37 47.

[25] M. Young, The Technical Writer's Handbook. Mill Valley, CA: University Science, 1989.

[26] H. Yoshida, Y. Li, The Japan Society for Aeronautical and Space Sciences, 49 (2006) 81-86.

[27] I. Taymaz, Surface \& Coatings Technology, 201 (2007) 5249-5252.

[28] A. Okada, Materials Science and Engineering B, 161 (2009) 182-187.

[29] T. Hejwowski, Vacuum, 85 (2010) 610-616.

[30] S. Sundaram, D.M. Lipkin, C.A. Johnson, J.W. Hutchinson, Journal of Applied Mechanics, 80 (2013) 1-13.

[31] V. Teixeira, Key Engineering Materials, 230-232 (2002) 335-338.

[32] G. Bolelli, V. Cannillo, L. Lusvarghi, R. Rosa, A. Valarezo, W.B. Choi, R. Dey, C. Weyant, S. Sampath, Surface and Coatings Technology, 206 (2012) 2585-2601.

[33] G. Udupa, S.S. Rao, K.V. Gangadharan, Procedia Materials Science, 5 (2014) 1291-1299.

[34] X.C. Zhang, B.S. Xu, H.D. Wang, Y. Jiang, Y.X. Wu, Thin Solid Films, 497 (2006) 223-231.

[35] G. Mirschel, K. Heymann, T. Scherzer, M.R. Buchmeiser, Polymer, 50 (2009) 1895-1900.

[36] I. Sheen, Sheen Instruments, Www.sheeninstruments.com, (2014).

[37] G. Mirschel, K. Heymann, T. Scherzer, Analytical chemistry, 82 (2010) 8088-8094.

[38] J.P. Cerisuelo, R. Gavara, P. Hernández-Muñoz, Packaging Technology and Science, 27 (2014) 901-920. 
About Author (s):

\begin{tabular}{|c|c|}
\hline Alias Mohd Noor \\
Research field : Experience in \\
automotive turbo-machinery, fluid \\
machinery, biotechnology (bio-fuels), \\
fluid mechanics, thermodynamics and \\
heat transfer, gas dynamics, internal \\
combustion engines and desalination \\
plants and now professor at Universiti \\
Teknologi Malaysia
\end{tabular}

\begin{tabular}{|c|c|}
\hline & $\begin{array}{c}\text { Muhammad Rabiu Abbas } \\
\text { Research field: Experience in solar } \\
\text { energy technology, wind energy } \\
\text { technology, automotive turbo } \\
\text { machinery, heat and mass transfer, } \\
\text { materials engineering and internal } \\
\text { combustion engines and now PhD } \\
\text { student at Universiti Teknologi } \\
\text { Malaysia }\end{array}$ \\
\hline
\end{tabular}

\begin{tabular}{|c|c|}
\hline Uday M. Basheer \\
Research field: Experience in \\
Advanced ceramic, Ceramic \\
composite insulators, ceramic / metal \\
joining, Friction welding, thermal \\
barrier coating, Metal alloy, Materials \\
characterizations and desalination \\
plants and now Senior Lecturer at \\
Universiti Teknologi Malaysia
\end{tabular}

